\title{
Brazilian studies on visual psychophysics and neurophysiology
}

\author{
MARIA LÚCIA DE B. SIMAS \\ Federal University of Pernambuco, Recife, Pernambuco, Brazil \\ and \\ JOSÉ APARECIDO DA SILVA \\ University of São Paulo at Ribeirão Preto, São Paulo, Brazil
}

\begin{abstract}
In Brazil, studies in visual psychophysics and neurophysiology are confined to a few small research groups located in some of the southeastern and northeastern cities. This paper provides a brief overview of these groups and the research they are carrying on.
\end{abstract}

There are very few studies developed and carried out in Brazil that could be considered to be strictly under the topic of visual psychophysics. This is, perhaps, because experimental psychology itself is yet to be fully developed as a strong research area in our country.

The present review is divided into two parts. The first part will describe an overview of the various research groups active in Brazil whose investigations are related to comparative psychophysics and neurophysiology, and the second part will describe the research being carried out by J. A. Da Silva, whose main experimental interest is to distinguish between the perceptual and cognitive factors affecting the perception of space, particularly the perception of size and distance, and that being carried out by Maria Simas on temporal frequency filtering by the human visual system. The main purpose of this article is to call attention to studies that are being developed in a country of the third world.

\section{BRAZILIAN STUDIES RELATED TO COMPARATIVE PSYCHOPHYSICS}

\section{University of São Paulo at São Paulo (USP/SP)}

A Brazilian group that is truly carrying on research in comparative psychophysics is that of Dora Ventura who works in the Sensory Psychophysics Laboratory at the Department of Psychology of USP/SP.

Ventura and her group study mainly the visual system of bees and ants. The studies on the spectral sensitivity of bee photoreceptors that include comparisons of species and methods (Hertel \& Ventura, 1985; Menzel, Ventura, Hertel, Souza, \& Greggers, 1986) are good examples of the type of investigation being carried on in this laboratory.

A version of this paper was read at the 24th International Congress of Psychology, Sydney, Australia. The preparation of this paper was supported by grants from Conselho Nacional de Desenvolvimento Científico e Tecnológico. Requests for reprints may be sent to J. A. Da Silva, Department of Psychology, University of São Paulo, 14.049 Ribeirão Preto, S.P., Brazil.
In the Menzel et al. (1986) study, three different methods were used to obtain estimates of the spectral sensitivity of the retinula cells in the compound eyes of the species Apis mellifera; Melipona quadrifasciata, and Osmia rufa. Using the traditional flash method, 300-msec flashes of monochromatic light were presented at 12 intensity levels and 19 wavelengths to the eye as a point light source (measuring $0.8^{\circ}$ of visual angle) centered to the recorded cell. A second method, the ramp method, made use of a logarithmic neutral density wedge mounted on a fast stepping motor to modulate the brightness of monochromatic light with a ramp. The speed of the stepping motor was adjusted to yield steps of $3 \mathrm{log} I$ units $/ 200 \mathrm{msec}$. Recorded responses were the number of steps performed by the motor as the cell reached a preselected DC potential. A third method, the spectral scanning method, was developed on the basis of studies by other researchers (e.g., Franceschini, 1984; Hardie \& Kirschfeld, 1983; Smakman \& Pijpker, 1983; as cited in Menzel et al., 1986). In this method, the response of the cell is expected to be fixed at a given DC potential and, as a grid monochromator scans through the spectrum (300-700 nm) with a resolution of $4 \mathrm{~nm}$, a neutral density wedge is turned by a stepping motor to adjust the brightness for responses deviating from the preselected DC potential. Each measurement cycle, through $400 \mathrm{~nm}$ of the spectrum, lasts $16 \mathrm{sec}$. Spectral scans were run in both directions for all cells. Any dependence on direction of scan was carefully inspected. The results with the latter method yielded narrow spectral sensitivity functions, and allowed Menzel et al. to conclude that "the high observed variability in the response of individual receptors is the result of the inadequacy of the flash method ... the only method used in earlier studies"' (p. 165).

Examples of other studies by the group include research on the distribution of color receptors within the ommatidium in bee photoreceptors (Ventura, Souza, Joaquim, \& Nassel, 1985), and research on the existence and function of extraocular cerebral photoreceptors in the ant (Nassel, Felisberti, \& Ventura, 10ミ5).

Recently, Souza and Ventura (1987) investigated temporal summation and critical duration in bee photorecep- 
tors, as part of a larger study that measured temporal summation with intracell recording in 10 insect species. Within the 10 studied species, the results, based on recordings from single retinula cells in the compound eyes, showed the critical duration to range between about $10 \mathrm{msec}$ to about $45 \mathrm{msec}$ under dark adaptation conditions. Smaller critical durations were typical of species of fast vision, while the converse was typical of species of slow vision. For the tropical bee Melipona quadrifasciata, temporal summation was measured by three different methods, since the ideal method, with allowance for dark adaptation between stimuli, would demand a period of time much longer than the duration of stable responses from the single retinular cells. The results showed equal-energy stimuli to yield a more precise evaluation of the degree of summation below the critical duration. Single pulses produced a deviation from Bloch's Law that was unexpected by the authors.

\section{Federal University of Pará (UFPA)}

In animal psychophysics, Luis Carlos L. Silveira and colleagues (Silveira, Picanço-Diniz, \& Oswaldo-Cruz, 1982) of the Department of Physiology, UFPA, measured the modulation transfer function of the opossum using visual-evoked potentials to obtain estimates of contrast sensitivity to phase reversing sinusoidal gratings. Maximum sensitivity was around 0.1-0.2 cycles per degree (cpd), while the average acuity value was $1.25 \mathrm{cpd}$. In another work, they investigated the refractive state of the eye of the opossum with electrophysiological techniques (Picanço-Diniz, Silveira, \& Oswaldo-Cruz, 1983). However, studies on comparative psychophysics by this research group are unusual, since they primarily are oriented towards visual neurophysiology.

\section{University of Brasilia (UnB)}

Another group carrying on research related to comparative psychophysics is that of Valdir Pessoa, who worked at the Federal University of Pernambuco's Department of Physiology and, since the beginning of 1988, has been working at the Department of Physiology of UnB. Pessoa and colleagues have been investigating the retinal organization of two species of sloths. Their main research is on visual system neurophysiology.

\section{Federal University of Rio de Janeiro (UFRJ)}

In animal research, the research groups at the Institute of Biophysics of UFRJ should be mentioned, although these groups are typically oriented towards both comparative neurophysiological and physiological research of the visual system of the monkey and the opossum.

Ricardo Gattass's group studies the visual topography of various species of monkeys (Gattass, Souza, \& Covey, 1985), and the groups of Carlos E. Rocha-Miranda and Eduardo Oswaldo-Cruz investigate the visual system of the opossum. In fact, the research groups at UFPA, UnB, and UFRJ are closely related.

Roberto Lent (e.g., Lent, 1982) and colleagues carry on comparative research of the consequences of induced disgenesis or transection of the corpus callosum of hamsters and is also interested in the observed behavioral effects.

\section{Federal University Fluminense (UFF)}

Working in a topic related to human psychophysics is Luiz G. Gawryszewski, who investigates attention mechanisms and interhemispheric connections using reaction-time procedures (e.g., Gawryszewski, Riggio, Rizzolatti, \& Umiltá, 1987; Riggio, Gawryszewski, \& Umiltá, 1986). He is presently at the Department of Neurobiology, UFF, at Rio de Janeiro.

\section{STUDIES ON THE PERCEPTION OF SIZE AND DISTANCE IN HUMAN PSYCHOPHYSICS AND ON TEMPORAL FREQUENCY FILTERING BY THE HUMAN VISUAL SYSTEM}

\section{University of São Paulo at Ribeirão Preto (USP/RP)}

In human psychophysics, J. A. Da Silva has been carrying on studies to distinguish between the perceptual and cognitive factors playing a role in perception of space, particularly in perceived size and distance. His work, in cooperation with Walter C. Gogel (Gogel \& Da Silva, 1987a, 1987b), summarizes these studies and evaluates their theory on the perception of size and distance.

The primary process, as expressed by the size-distance invariance hypothesis, concerns the interrelation of perceived size and perceived distance, independent of information derived from memory or suggestion. The secondary process involves information regarding size (from memory or suggestion) not contained in the immediate visual stimulus. If the primary and secondary sources of size information differ, the object is seen as off-sized. This off-sized perception can be used to modify the direct report of the distance of the object. In casual suggestion of size, the off-sized judgment produces a nonperceptual (cognitive) report of distance (Gogel, 1981). In memory of the size of a familiar object, some of the effect on the direct report of perceived distance is perceptual, but most is cognitive (Gogel, 1976). In optical expansion, the effect of off-sized judgments on distance responses produces a clear modification of perceived distance (Swanston \& Gogel, 1986). The experimental distinction between primary and secondary processes is facilitated by comparing measures of perceived distance obtained from direct procedures (e.g., verbal reports of distance) with those obtained from indirect procedures (e.g., the headmotion procedure). The former (direct) methods reflect both primary and secondary sources of information. The latter (indirect) methods are sensitive only to primary sources.

\section{Federal University of Pernambuco (UFPE)}

At the Department of Psychology of UFPE, Maria Simas is developing a laboratory of visual perception to carry on electrophysiological and psychophysical research of the human visual system. The research reported here 
on temporal filtering by the human visual system was performed at the Department of Psychology of Queen's University of Kingston, Kingston, Ontario, Canada, in cooperation with Michael von Grünau.

This research was performed to investigate the results on perception of complex flicker phenomena by Levinson $(1959,1960)$ who suggested that the human visual system was composed of multiple narrow-band filters tuned to different ranges of temporal frequency. Many studies, such as those by Smith $(1970,1971)$, have tested Levinson's hypothesis using the adaptation paradigm of Blakemore and Campbell (1969) and temporal frequency stimuli to obtain estimates of temporal frequency filters' bandwidths. The initial results from the studies by Smith showed smaller effects than those found in the results from spatial frequency adaptation. Later results confirmed that tendency. The study we present here summarizes a series of experiments, carried out by Maria Simas and her colleagues, that investigated the existence of temporal frequency filters using a novel method designed to be the temporal analogue of the spatial frequency adaptation technique.

In this novel technique, the adaptation and the test stimuli are presented simultaneously, instead of contiguously in time. Based on linear systems theory, two typical response functions (responses to homogeneous luminance fields' flickering modulated either by sine waves of varying temporal frequencies or by square waves of varying fundamental frequencies) were selected to characterize each of three filters tuned to either 5,10 , or $15 \mathrm{~Hz}$. Linearity and time invariance were also checked for each filter. Estimates of each response function were based on at least nine points, each point being measured at least twice in different days. The results are based on a total of about 171 experimental sessions lasting between 20 and $45 \mathrm{~min}$, with 70 to 100 forced-choice trials in each measurement. The apparatus specifically designed for these experiments had a $10.3 \times 13.2 \mathrm{~cm}$ milky acrylic display, lying over three horizontal divisions $1^{\circ}$ of visual angle high. Inside each division were fluorescent lights that could be controlled independently by two function generators to modulate the stimulus either by sine- or squarewave functions. Brightness amplitude was maximum (1.2 log units above threshold) inside the center aperture where the adapting stimulus was presented, and was close to threshold inside either the upper or lower division where the test stimulus was presented. The exact locus of presentation of the test stimulus varied randomly from trial to trial. Given the unusually high number of experimental sessions, only 1 observer was run in the experiment, which lasted for about 23 weeks. The results suggest the existence of at least three distinct mechanisms (multiple peak filters). However, only one mechanism $(10 \mathrm{~Hz})$ showed results compatible with linearity and time invariance. Furthermore, all three mechanisms showed high sensitivity to two $(5$ and $10 \mathrm{~Hz})$ or three $(15 \mathrm{~Hz})$ temporal frequency ranges. These results lead to the conclu- sion that, although the novel technique yields effects with magnitudes equivalent to those obtained for spatial frequencies with the adaptation paradigm, there seem to exist no temporal filters, as suggested by Levinson. The underlying mechanisms appear to have multiple peaks and broad spectrum.

\section{CONCLUSION}

The results reported here show the major trends in visual psychophysics and neurophysiology in Brazil. Most of the studies are being done (or were done) in cooperation with universities or research institutes from a variety of countries, including the U.S.A., West Germany, Italy, and Canada. The stronger research groups, which have well-equipped laboratories, are found in São Paulo state, Rio de Janeiro state, and Brasilia (Federal District). However, other small groups are being developed in the north and northeast regions. We hope to be able to show quite a different overview in another 10 years.

\section{REFERENCES}

Blakemore, C., \& Campbell, F. W. (1969). On the existence of neurons in the human visual system selectively sensitive to the orientation and size of retinal images. Journal of Physiology, 203, 237-260.

Gattass, R., SouzA, A. P. B., \& Covey, E. (1985). Cortical visual areas of the macaque: Possible substrates for pattern recognition mechanisms. Pontificiae Academiae Scientiarum Scripta Varia, 54, 1-20.

Gawryszewski, L. de G., Riggio, L., Rizzolatti, G., \& Umiltá, C. (1987). Movements of attention in the three spatial dimensions and the meaning of "neutral" cues. Neuropsychologia, 25, 19-29.

GoGEL, W. C. (1976). An indirect method of measuring perceived distance from familiar size. Perception \& Psychophysics, 20, 419-429.

GoGEL, W. C. (1981). The role of suggested size in distance responses. Perception \& Psychophysics, 30, 149-155.

Gogel, W. C., \& DA Silva, J. A. (1987a). Familiar size and the theory of off-sized perceptions. Perception \& Psychophysics, 41, 318-328.

Gogel, W. C., \& DA Silva, J. A. (1987b). A two-process theory of the response to size and distance. Perception \& Psychophysics, 41, 220-238.

Hertel, H., \& Ventura, D. F. (1985). Spectral sensitivity of photoreceptors in the compound eye of stingless tropical bees. Journal of Insect Physiology, 31, 931-935.

LENT, R. (1982). Reorganization of interhemispheric connections in hamsters with surgically induced disgenesis of the corpus callosum. Neuroscience, 7, S130.

LEVINSON, J. (1959). Fusion of complex flicker. Science, 130, 919-921.

Levinson, J. (1960). Fusion of complex flicker. Part II. Science, 131, 1438-1440.

Menzel, R., Ventura, D. F., Hertel, H., Souza, J. M., \& GregGERS, U. (1986). Spectral sensitivity of photoreceptors in insect compound eyes: Comparison of species and methods. Journal of Comparative Physiology A, 158, 165-177.

Nassel, D. R., Felisberti, F. M., \& Ventura, D. F. (1985). Extraocular cerebral photoreceptors in an ant. Brazilian Journal of Medical \& Biological Research, 18, 632A.

Picanço-Diniz, C. W., Silveira, L. C. L., \& Oswaldo-Cruz, E. (1983). Electrophysiological determination of the refractive state of the eye of the opossum. Vision Research, 23, 867-872.

Riggio, L., Gawryszewski, L. DE G., \& Umiltá, C. (1986). What is crossed in crossed-hand effects? Acta Psychologica, 62, 89-100. Silveira, L. C. L, Picanço-Diniz, C. W., \& Oswaldo-Cruz, E. 
(1982). Contrast sensitivity function and visual acuity of the opossum. Vision Research, 22, 1371-1377.

SMITH, R. A. (1970). Adaptation of visual contrast sensitivity to specific temporal frequencies. Vision Research, 10, 275-279.

Smith, R. A. (1971). Studies on temporal frequency adaptation in visual contrast sensitivity. Journal of Physiology, 216, 531-552.

SouzA, J. M., \& Ventura, D. F. (1987). Temporal summation and critical duration in bee photoreceptors: A comparison of measurement methods. Brazilian Journal of Medical \& Biological Research, 20, 649-652.
Swanston, M. T., \& Gogel, W. C. (1986). Perceived size and motion in depth from optical expansion. Perception \& Psychophysics, 39, 309-326.

Ventura, D. F., Souza, J. M., Joaquim, L. C. M., \& Nassel, D. R. (1985). Bee photoreceptors: Spectral sensitivity, morphology and central connections. Brazilian Journal of Medical \& Biological Research, 18, 632A.

(Manuscript received September 15, 1988.) 